\title{
Montane meadow change during drought varies with background hydrologic regime and plant functional group
}

\author{
Diane M. Debinski,${ }^{1,5}$ Hadley Wickham,${ }^{2}$ Kelly Kindscher,${ }^{3}$ Jennet C. Caruthers, ${ }^{1}$ and Matthew Germino ${ }^{4}$ \\ ${ }^{1}$ Ecology, Evolution, and Organismal Biology, Iowa State University, Ames, Iowa 50011 USA \\ ${ }^{2}$ Statistics Department, Iowa State University, Ames, Iowa 50011 USA \\ ${ }^{3}$ Kansas Biological Survey, 2021 Constant Avenue, University of Kansas, Lawrence, Kansas 66047-2906 USA \\ ${ }^{4}$ Department of Biology, Idaho State University, Pocatello, Idaho 83209 USA
}

\begin{abstract}
Climate change models for many ecosystems predict more extreme climatic events in the future, including exacerbated drought conditions. Here we assess the effects of drought by quantifying temporal variation in community composition of a complex montane meadow landscape characterized by a hydrological gradient. The meadows occur in two regions of the Greater Yellowstone Ecosystem (Gallatin and Teton) and were classified into six categories (M1-M6, designating hydric to xeric) based upon Satellite pour l'Observation de la Terre (SPOT) satellite imagery. Both regions have similar plant communities, but patch sizes of meadows are much smaller in the Gallatin region. We measured changes in the percent cover of bare ground and plants by species and functional groups during five years between 1997 and 2007. We hypothesized that drought effects would not be manifested evenly across the hydrological gradient, but rather would be observed as hotspots of change in some areas and minimally evident in others. We also expected varying responses by plant functional groups (forbs vs. woody plants). Forbs, which typically use water from relatively shallow soils compared to woody plants, were expected to decrease in cover in mesic meadows, but increase in hydric meadows. Woody plants, such as Artemisia, were expected to increase, especially in mesic meadows. We identified several important trends in our meadow plant communities during this period of drought: (1) bare ground increased significantly in xeric meadows of both regions (Gallatin M6 and Teton M5) and in mesic (M3) meadows of the Teton, (2) forbs decreased significantly in the mesic and xeric meadows in both regions, (3) forbs increased in hydric (M1) meadows of the Gallatin region, and (4) woody species showed increases in M2 and M5 meadows of the Teton region and in M3 meadows of the Gallatin region. The woody response was dominated by changes in Artemisia spp. and Chrysothamnus viscidiflorus. Thus, our results supported our expectations that community change was not uniform across the landscape, but instead could be predicted based upon functional group responses to the spatial and temporal patterns of water availability, which are largely a function of plant water use and the hydrological gradient.
\end{abstract}

Key words: drought; forbs; Greater Yellowstone Ecosystem; hydrological gradient; plant community; woody plants.

\section{INTRODUCTION}

Climate change monitoring, analyses, and predictions rarely consider heterogeneity at the field or plot scale. Yet climate sensitivity must vary considerably within landscapes, because both microclimate and organismal response to climate vary within landscapes. Understanding the potential for heterogeneity in climate responses is essential in the process of understanding climate responses overall. In the western United States, one of the most important environmental issues is that of recurring drought (Cook et al. 2007), so there is much interest in how global climate change may affect water availability at the regional to local scale. Changes in the

Manuscript received 30 March 2009; revised 18 September 2009; accepted 23 September 2009. Corresponding Editor: R. W. Ruess.

${ }^{5}$ E-mail debinski@iastate.edu amount and timing of precipitation are also of interest because patterns of water availability determine the plant and animal communities that can be supported.

Regional models of climate change for the northern Rocky Mountains predict warmer temperatures (Reiners et al. 2003) and Western states have shown a trend in recent decades toward increases in the fraction of precipitation falling as rain rather than snow (Mote et al. 2005, Knowles et al. 2006). The western United States has generally been characterized by a hotter and drier climate, with an average of $0.5^{\circ} \mathrm{C}$ temperature increase during 2003-2007 as compared to the 20th century average (Saunders et al. 2008). All of these changes point to drier conditions during mid- to late summer.

Within the Rocky Mountain region, the Greater Yellowstone Ecosystem (GYE) is one of the few, large-scale, relatively pristine ecosystems in the contig- 
uous United States, so it provides an excellent area for the examination of biotic responses to climatic variation. Montane meadows of the GYE exist in a predominantly arid environment and are arrayed along a hydrological gradient (hydric to mesic to xeric) with their boundaries defined by soil type, soil moisture, and disturbances such as herbivory and fire (Marston and Anderson 1991). This hydrological gradient creates a mosaic of plant communities and concurrently a mosaic of potential responses to water availability. Here we report on the changes in percent cover by two major plant functional types (forbs and woody species) as well as bare ground for the period 1997-2007, which includes a substantial drought period. We hypothesized that the effects of drought would not likely be applied evenly across a landscape that is influenced by variations in soil moisture. Instead, we expected heterogeneity in climate sensitivity, including hotspots of change and areas with less change. We expected that the most hydric meadows would not be significantly affected by drought because their topographic position ensures saturation. Conversely, meadows that are relatively xeric would already be adapted to drought conditions and would not show strong responses to episodic or early-season drought. We expected that meadows in the middle of the gradient (mesic) would be most vulnerable to extended drought.

Within each of these meadows, we expected that relative abundances of plant functional groups could change because shallower-rooted plant species utilize intermittently available water from summer rains, whereas deeper-rooted species rely more on precipitation stored in deep soils during snowmelt (Dodd et al. 1998, Williams and Ehleringer 2000). Water storage in the deeper soils disconnects growth resources from interannual climate variability, buffering deeper-rooted species. The longer life span of woody species also provides a buffer from interannual variability in climate, or "storage effect" (Chesson 2000). In this study, we did not directly measure soil moisture, but rather we measured differential responses of the functional groups, which may be an indication of conditions in different horizons of the soil. Previous studies in the GYE have shown that water availability in shallow soils is substantially more variable than that of deeper soils (Hill et al. 2006, Prevey et al. 2009), similar to the pattern well known for many dryland systems (NoyMeir 1973).

Because the majority of plant species in these communities are perennial, we hypothesized that shortterm changes in environmental conditions would be manifested as changes in plant community cover. We hypothesized that herbaceous species (forbs), which are generally using water from the upper soil horizons, would show the strongest responses to drought. Specifically, we expected a reduction in the percent cover of forbs in mesic meadows as they become drier. Conversely, we expected the potential for compensatory increases in woody species such as Artemisia (sagebrush), which

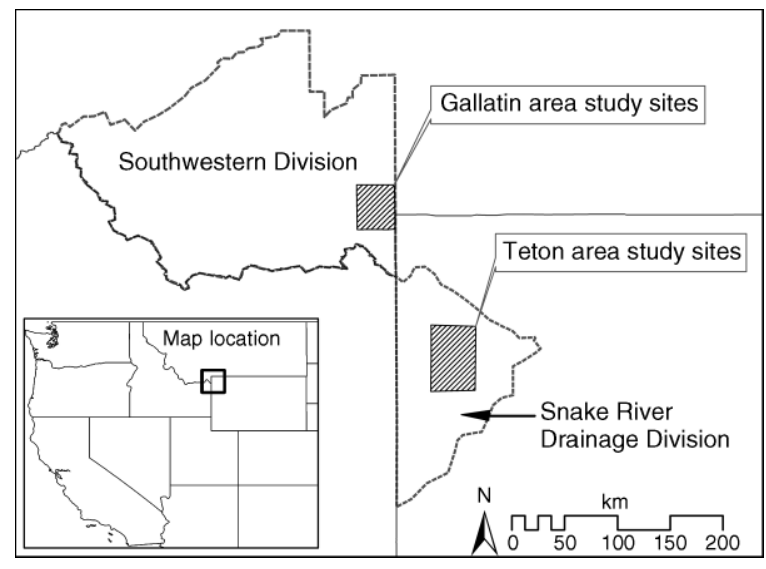

Fig. 1. Map of Gallatin and Teton study regions of the Greater Yellowstone Ecosystem in the western United States relative to National Climate Data Center Palmer Drought Severity Index (PDSI) climatic divisions: the Southwestern Division of Montana and the Snake River Division of Wyoming. Data were derived from National Climate Data Center (2009b).

use water from deeper soil horizons (Cook and Lewis 1963, Sturges 1973, Richards and Caldwell 1987).

\section{Materials And Methods}

\section{Study area}

Our sampling sites were located in two regions of the Greater Yellowstone Ecosystem: the northern region (hereafter termed the "Gallatin region") included the Gallatin National Forest (see Plate 1) and northwestern portion of Yellowstone National Park; the southern region (hereafter termed the "Teton region") included Grand Teton National Park. These two regions are 192 $\mathrm{km}$ apart, but have very similar plant and animal communities (Debinski et al. 2000, 2002). Maps depicting detailed locations of each of the study sites can be found in Saveraid et al. (2001). Fig. 1 shows the Gallatin and Teton study regions within the context of National Climate Data Center (NCDC) division mapping regions. The largest difference between the two study regions is that the Gallatin region has smaller average meadow patch sizes (e.g., meadow areas of 1-10 ha) compared to the Teton region (e.g., meadow areas of hundreds to thousands of hectares) and is separated by ridges of mountains, whereas the Teton region has much larger patches located within the Jackson Hole valley of Wyoming (Debinski et al. 2001, Caruthers 2008).

We previously used Satellite pour l'Observation de la Terre (SPOT; SPOT Image Corporation, Toulouse, France) multi-spectral satellite imagery to identify and map montane meadow types ( $\mathrm{M}$ types) along the hydrological gradient (Debinski et al. 1999) and to develop spectrally based, spatially explicit models for predicting species diversity patterns based on meadow type (Debinski et al. 2000). This classification represented a hydrologic gradient such that meadows were categorized into six meadow types, ranging from hydric 


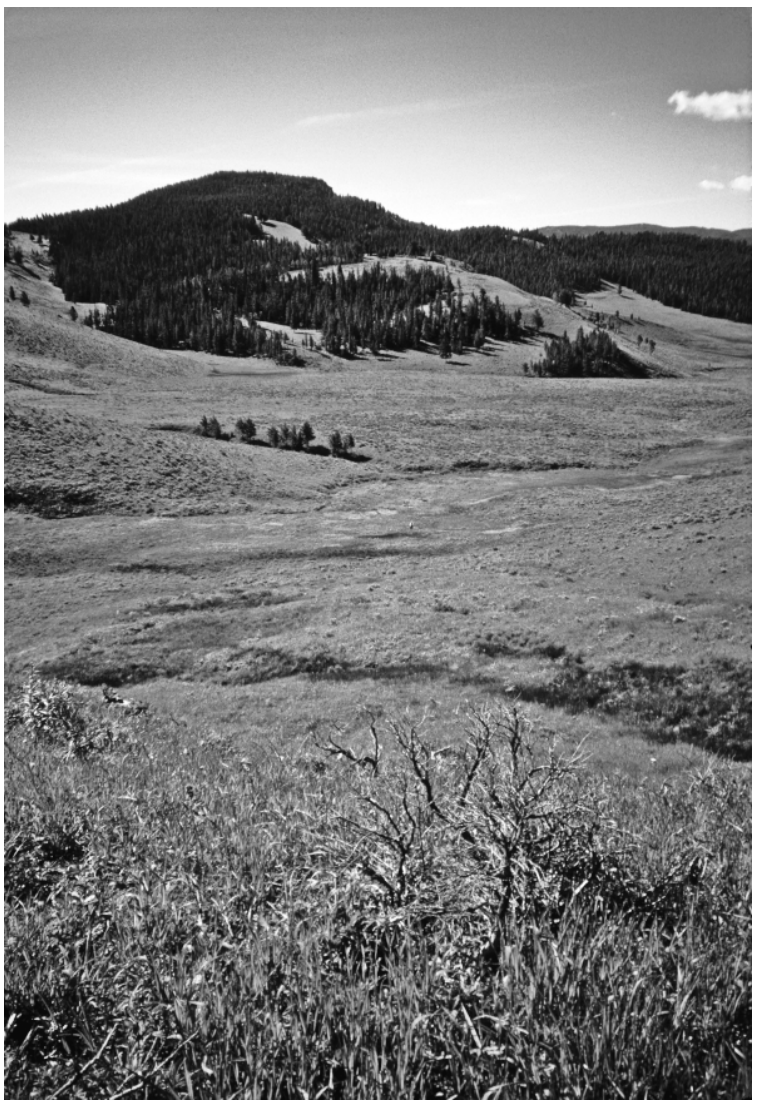

Plate 1. The landscape mosaic of different meadow types is exemplified here by Teepee Creek in the Gallatin National Forest, Montana, USA. Darker regions represent wetter (hydric) sedge (Carex) meadows, while lighter regions represent drier (xeric) sagebrush (Artemisia) meadows. Photo credit: D. M. Debinski.

(M1) to xeric (M6) meadows. Field surveys of plant communities confirmed the predicted moisture gradientjnhj and that we could classify specific subsets of montane meadow types such as wetland and sagebrush communities (Jakubauskas et al. 1998, 2001, Kindscher et al. 1998, Debinski et al. 2000). The M1 and M2 meadows are willow (Salix spp.) thickets and sedge (Carex spp.) marshes, respectively, with some ephemeral standing water. The M2 meadows have the highest graminoid biomass. The M3 meadows are mesic meadows characterized by high forb biomass and diverse forb and grass composition. The M4 meadows have cinquefoil (Potentilla spp.) and mixed herbaceous vegetation, while M5 meadows have a mixture of sagebrush (Artemisia tridentata) and herbaceous vegetation. The M6 meadows are characteristically xeric, rocky, and dominated by sagebrush.

\section{Selection of sampling sites}

Five spatially distinct examples of each meadow type in each region were selected within an elevation range of $2000-2500 \mathrm{~m}$. Although there was the opportunity to examine the effects of elevation, we intentionally "factored out" elevation by holding this variable as constant as possible. Because there are no M4 meadows in the Teton region, we sampled 30 sites in the Gallatin region and 25 sites in the Teton region. Meadows were characterized as suitable survey sites if they were within $8 \mathrm{~km}$ from a road or trail, a minimum of $100 \times 100 \mathrm{~m}$, no more than $2 \mathrm{~km}$ on a side, and at least $500 \mathrm{~m}$ from another meadow site (Debinski et al. 2001). A $20 \times 20 \mathrm{~m}$ sampling area was established relative to a point chosen in a central and representative portion of each meadow. This center point was the northwest corner of a $20 \times 20$ $\mathrm{m}$ plot used for plant surveys during 1997-2001. This center point became the southeast corner of the plant survey plots during 2006 and 2007, but given the homogeneous nature of the plots as defined by the spectral data and minimum size rules for use in the study, exact placement of the plot was not necessary to quantify changes at a scale of $20 \times 20 \mathrm{~m}$ vegetation survey plots.

\section{Vegetation sampling techniques}

At each of the 55 study sites, vegetation was surveyed once per season in the middle of the growing season (July) in $20 \times 20 \mathrm{~m}$ plots during 1997, 1998, 2001, 2006, and 2007. Aerial cover estimations were conducted using a modified Daubenmire (1959) method in which we attempted to sample the cover of each species or species group to the nearest percent. This was done by walking back and forth in transects across the entire $20 \times 20 \mathrm{~m}$ area and estimating the cover of each species individually within a $\sim 3 \mathrm{~m}$ wide window of space in front of the observer and then summing these transect estimates for a species-level estimate of the entire plot. The combined percent cover of litter and bare ground was also estimated. Cover estimates were made for all plants in each plot at the species level for the 1997, 1998, and 2001 surveys. These surveys were repeated in 2006 and 2007, focusing on estimates of cover for the 10-12 most common forbs (by species in most cases and by genus for a few groups), bare ground, and woody plants by genus (primarily Artemisia and Salix). Cover was summed across estimates within each functional group by site and year to calculate the total cover during each year of sampling for bare ground, forbs, dominant forbs, and woody plants. Voucher specimens were collected for all species so that accurate identifications could be made in consultation with the University of Kansas Herbarium.

\section{Biomass composition by meadow type}

Plant biomass measurements were made in July of 1997 for both Teton and Gallatin regions. For each plot, three $0.20 \times 0.50 \mathrm{~m}\left(0.1-\mathrm{m}^{2}\right)$ quadrats were spaced at $10.0-\mathrm{m}$ intervals along the northern edge of each $20 \times 20$ $\mathrm{m}$ plant community survey plot. All aboveground green photosynthetically active vegetation (not including woody parts) within each quadrat was clipped, sorted 
by functional group (graminoids, forbs, and shrubs), placed in paper bags, and immediately weighed in the field using spring scales to the nearest $1.0 \mathrm{~g}$ to determine wet mass.

\section{Climate data}

The Palmer Drought Severity Index (PDSI) was used as an index of drought conditions during the time of our study and to make comparisons with historic conditions. The PDSI is calculated based upon temperature, precipitation, available water capacity of the soil, and heat index data (Karl 1986). We used drought severity index data for the month of August to summarize annual conditions during the growing season because, by definition, the PDSI values incorporate the months prior to the time of estimation. PDSI data from 1895 to 2007 were downloaded from the National Climate Data (National Climate Data Center 2009a) website at the division (substate data) level for southwest Montana (Gallatin region) and for the Snake River drainage of Wyoming (Teton region; Fig. 1). We then averaged the annual August values for each of the two stations to estimate an annual PDSI value for the overall GYE region.

\section{Statistical analysis of trends}

For each site and plant type, the mean yearly change in cover was summarized with a single number, the "multiplicative change in percent cover" (MCPC), determined for each functional group or plant species for each of the 55 sites. The MCPC is derived from a simple geometric model with parameters $C$ (percent cover) and $\lambda$ (growth rate, which is MCPC):

$$
C_{t}=C_{0} \lambda^{t}
$$

where $C_{0}$ is the percent cover at time $0 ; C_{t}$ is the percent cover at time $t$ (years since start); $\lambda$ is growth rate, MCPC. The MCPC can be determined from ordinary linear regression given the following:

$$
\begin{aligned}
& \log \left(C_{t}\right)=\log \left[C_{0}(\lambda)^{t}\right] \\
& \log \left(C_{t}\right)=\log \left(C_{0}\right)+t \log (\lambda) .
\end{aligned}
$$

The log of MCPC is determined as the slope of the log percent cover plotted against time. A linear trend on the log scale implies a geometric trend on the original scale, so this model predicts a constant percentage increase (or decrease) each year. As in logistic population growth equations, values of $\mathrm{MCPC}>1$ indicate an increase in percent cover over time, whereas MCPC values $<1$ indicate a decrease in percent cover over time. Over a decade, a small MCPC value can lead to significant changes in percent cover at the landscape scale.

To use MCPC to examine the effect of meadow type (and region), we treated $\mathrm{MCPC}$ as a response variable, summarizing a complicated pattern of change into a single representative number. In order to test which inputs most affected the MCPC, we used an ANOVA with one continuous response (MCPC) and two categorical predictors (meadow type and region). The results from the ANOVAs were summarized with plots showing the MCPC least square means for the combination of meadow type and plant type, within a region. Tukey's honestly significant difference (hsd) test was used to adjust for the multiple comparisons. Cases in which a species cover was not estimated for a particular year were treated as missing values (not zeros), so these values did not affect the estimate of MCPC.

We used this approach because the raw cover data were noisy and fitting a hierarchical model that combined individual species trends with global site trends was computationally and cognitively prohibitive. A geometric trend at the species level is biologically plausible, and little information was lost by taking this approach.

Vegetation survey data were grouped as follows: bare ground, forbs, dominant forbs, and shrubs (woody plants). The forb category included the summed cover for all forb species for which data were collected during each of the five years of sampling (either at genus level or species level). A second category, dominant forbs, represented a smaller subset of the forb species for which cover was specifically estimated at the species level during each of the five years (40 species). These species were, by definition, those that made up the highest percent cover in each of the meadow types. Thus, the cover estimates for dominant forbs represent a much smaller total number of species, but also a much more conservative estimate of trends. Each group was then tested for temporal trends over the period 1997-2007. Individual species (and in some cases genera for woody species) were also examined for trends. We focused on species and genera that had the highest mean percent cover $(>1 \%)$ within each meadow type and tested for significant trends over time in the same way as for plant functional groups.

Because we estimated percent cover for every grass, rush, and sedge species at the species level in 1997, 1998, and 2001 and as a group (graminoids) in 2006 and 2007, we did not include a temporal analysis of graminoids as a functional group. We were concerned that total percent cover would be underestimated in later years in comparison to earlier years due to the large number of overlapping canopy layers (e.g., several overlapping species could result in a maximum graminoid cover value $>100 \%$ if each of these values was estimated individually and then summed, compared to a maximum cover value of $100 \%$ if they were estimated as a group). This effect could potentially bias our data toward finding a spurious decreasing trend.

\section{Results \\ Climate data}

The beginning of our project (1997-1999) was characterized by above-normal to normal moisture 


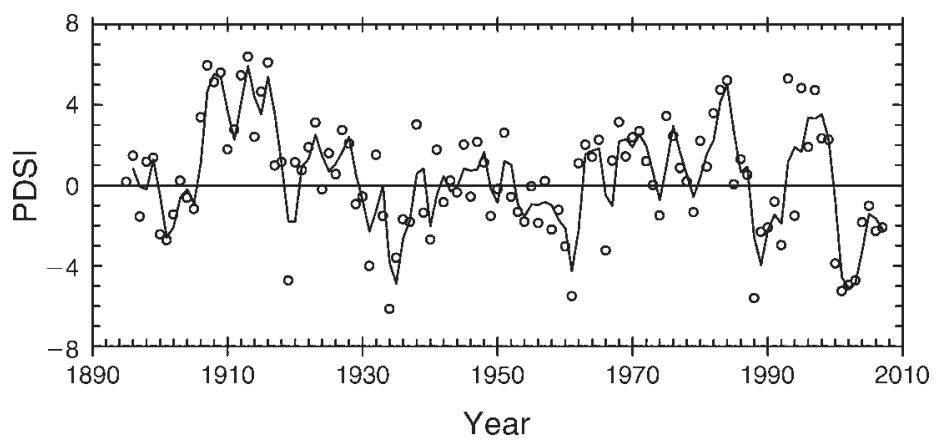

FIG. 2. The Palmer Drought Severity Index (PDSI) for the month of August annually from 1895 to 2007 within the study region. Data are based on average annual August PDSI values for each of the two climate regions (the Southwestern Division of Montana and the Snake River Division of Wyoming). Points show actual data for each year; the trend line shows a two-year running average. The drought index indicates the severity of a wet or dry spell and is based on the principles of a balance between moisture supply and demand. The index generally ranges from -6 to +6 , with negative values denoting dry spells and positive values indicating wet spells. PDSI values 0 to -0.5 , normal; -0.5 to -1.0 , incipient drought; -1.0 to -2.0 , mild drought; -2.0 to -3.0 , moderate drought; -3.0 to -4.0 , severe drought; and greater than -4.0 , extreme drought. Similar adjectives are attached to positive values of wet spells.

conditions, but 2000-2007 was characterized by mild to extreme drought conditions. The period 2000-2003 was extremely dry, with sustained PDSI values near or exceeding -5 and includes the driest consecutive fouryear period during the entire 112-year time series of instrumental data collection (Fig. 2). The period 20042007 continued to show drought conditions, with an average PDSI value in the range of -2 .

\section{Biomass data}

The fraction of community biomass that was classified as shrub was greatest in the hydric and the xeric meadows (Fig. 3). Total aboveground biomass was higher in the Teton region than in the Gallatin region, but general composition patterns were similar.

\section{Changes in cover by functional groups}

Over the 10 study years, (1) bare ground increased significantly in xeric meadows of both regions (Gallatin M6 and Teton M5) and in mesic (M3) meadows of the Tetons, (2) forbs decreased significantly in the mesic (M3 and M4) and xeric (M6) meadows in both regions, (3) there was a marginally significant trend toward increasing dominant forbs in hydric (M1) meadows of the Gallatin region $(P=0.054)$, and (4) woody species showed increases in M2 and M5 meadows of the Teton region and in M3 meadows of the Gallatin region (Fig. 4). Both forbs and dominant forbs showed similar trends, especially in the mesic meadows, reinforcing our confidence in our assessment of the overall forb response.

Several of the estimates of multiplicative change in percent cover of shrubs, forbs, and bare ground also showed significant differences across regions and meadow types (Fig. 4). Differences between the two study regions were most strongly observed in the forb responses. Gallatin forb and dominant forb responses showed more significant responses across meadow types

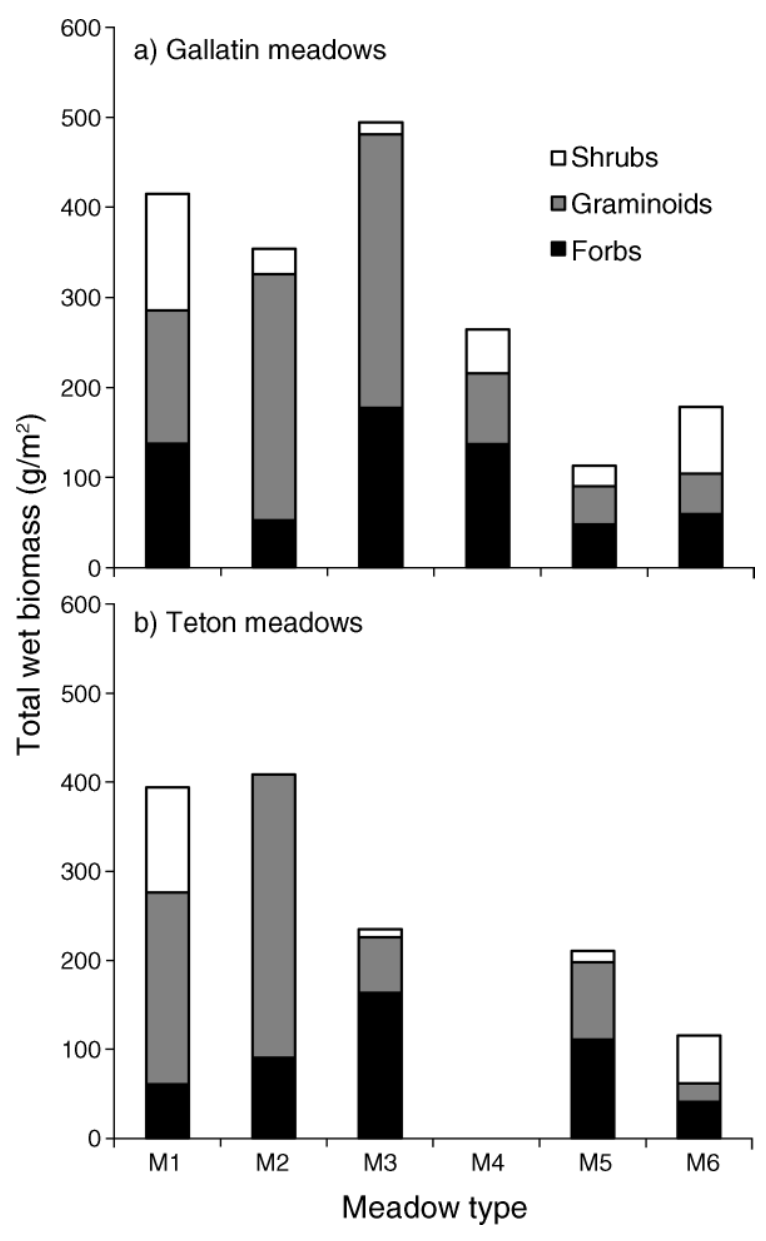

FIG. 3. Total aboveground wet biomass composition by functional group (shrubs, graminoids, forbs) of (a) Gallatin and (b) Teton meadows by meadow type. See Table 1 for an explanation of meadow-type abbreviations. 


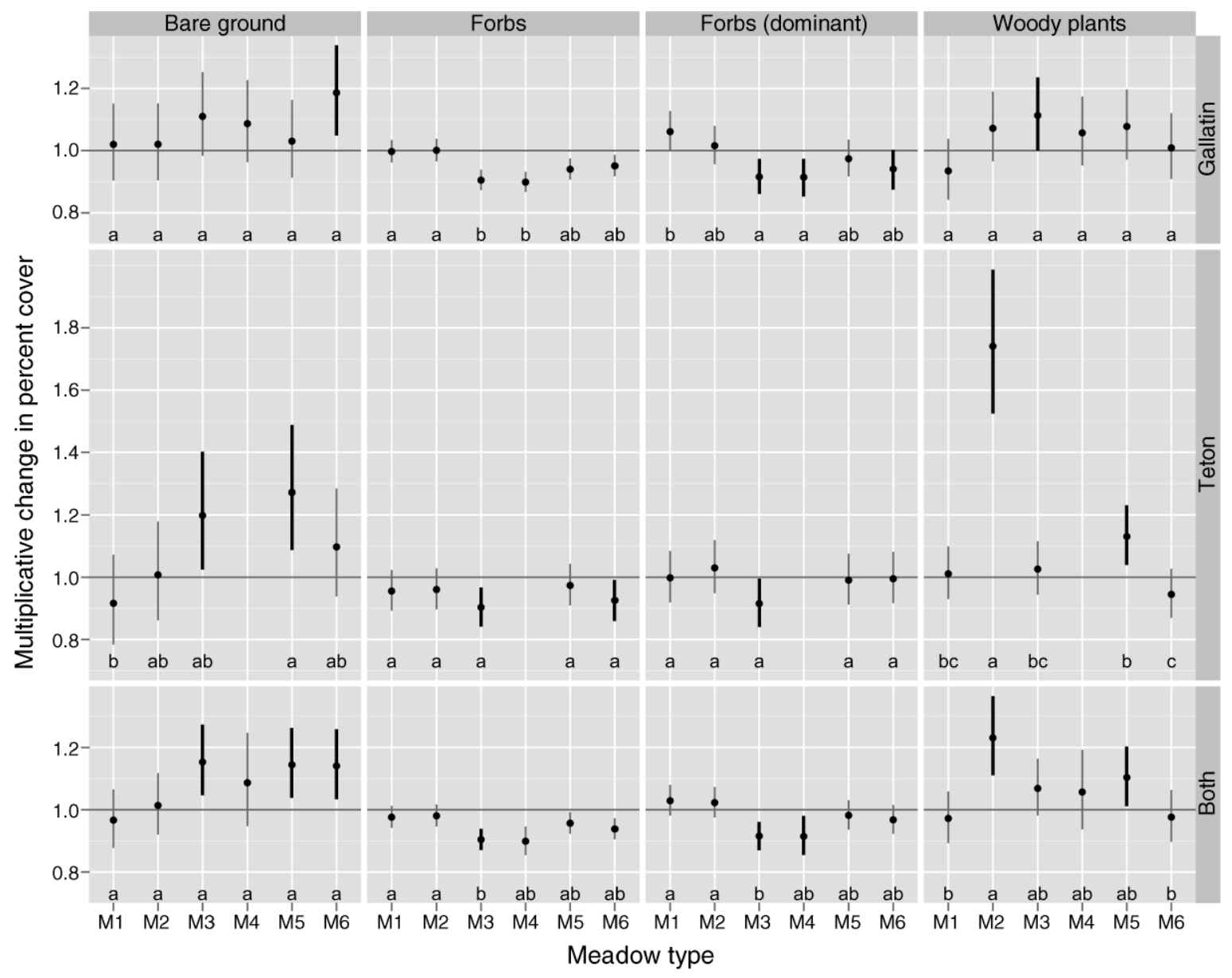

FIG. 4. Least-squares estimates of multiplicative change in percent cover over five sampling dates from 1997 to 2007 , for each combination of meadow type and cover type. M1-M6 categorization represents a hydric to xeric gradient of meadows (see Table 1 for a detailed explanation of meadow-type abbreviations). The top row of panels represents the 30 Gallatin sites, the middle row represents the 25 Teton sites, and the bottom row represents the 55 Gallatin and Teton sites analyzed together. Point estimates for average multiplicative change across all species within a functional group are plotted. Vertical lines for each datum represent the 95\% confidence interval around the mean, and different letters designate significant differences among meadow types within a cover type $(\alpha=0.05)$. Pairwise contrasts are adjusted for multiple comparisons using Tukey's method. Significant changes $(\alpha=0.05)$ are denoted by bold lines. Note that the change in forbs (dominant) for M1 meadows in the Gallatin region is not denoted in bold, but was marginally significant at $P=0.054$.

than Teton meadows. Comparing across meadow types, the MCPC of forbs showed significantly stronger declines in M3 and M4 meadows compared to hydric meadow types in the Gallatin region. In contrast, M1 meadows showed a modest increase in dominant forbs that differed significantly from the negative response of the mesic meadows in the Gallatin region. The response of bare ground in Teton meadows was significantly different in M5 meadows (significant increase) as compared to M1 meadows (nonsignificant decrease). Woody species in M2 meadows of the Teton region also showed a much stronger response than seen in any of the other Teton meadows. Examining the two regions combined, both forbs and dominant forbs showed significantly stronger declines in M3 meadows compared to hydric meadows, and M2 meadows showed significantly larger increases in woody plants (primarily Salix) compared with M1 or M6 meadows. However, we believe that the increase in shrubs in the Teton M2 meadows may be an outlier. Because M2 meadows are dominated by graminoids, the percent cover of woody species tends to be very low in M2 sites. As a result, a small difference in estimation of woody cover could have a large effect on the results. We also had limited access to some of these sites due to grizzly bear (Ursus horribilis) activity in 2007. The missing data combined with the low cover values may serve to inflate the estimated changes.

\section{Changes in individual species}

Individual species of forbs and woody plants also showed significant trends (Table 1). Of the 40 dominant forb species, 13 showed significant trends in abundance over the study period. All but one of these forb species 
TABle 1. Species and cover types with significant trends $(P \leq$ $0.05)$ in multiplicative change in percent cover (MCPC) in two regions of the Greater Yellowstone Ecosystem $(\mathrm{G}$, Gallatin; T, Teton) by meadow type (Mtype) from 1997 to 2007.

\begin{tabular}{lcccc}
\hline \hline \multicolumn{1}{c}{ Species } & Region & Mtype & MCPC & $P$ \\
\hline Achillea millefolium & G & M3 & 0.88 & 0.01 \\
Achillea millefolium & G & M4 & 0.89 & 0.02 \\
Arenaria congesta & T & M3 & 0.78 & 0.00 \\
Artemisia tridentata & G & M3 & 1.27 & 0.01 \\
Symphyotrichum campestre & G & M6 & 0.86 & 0.02 \\
Bare ground & G & M6 & 1.19 & 0.01 \\
Bare ground & T & M3 & 1.18 & 0.03 \\
Bare ground & T & M5 & 1.26 & 0.00 \\
Campanula rotundifolia & T & M3 & 0.97 & 0.04 \\
Chrysothamnus viscidiflorus & G & M5 & 1.09 & 0.00 \\
Cirsium scariosum & G & M1 & 0.94 & 0.00 \\
Cirsium scariosum & T & M3 & 1.07 & 0.00 \\
Collomia linearis & T & M3 & 0.92 & 0.01 \\
Eriogonum umbellatum & T & M3 & 0.87 & 0.02 \\
Fragaria virginiana & G & M4 & 0.86 & 0.02 \\
Fragaria virginiana & T & M3 & 0.75 & 0.01 \\
Geum triflorum & T & M2 & 0.75 & 0.01 \\
Geum triflorum & T & M3 & 0.84 & 0.01 \\
Linum lewisii & G & M3 & 0.83 & 0.00 \\
Lupinus argenteus & T & M3 & 0.86 & 0.04 \\
Perideridia gairdneri & G & M3 & 0.90 & 0.02 \\
Potentilla gracilis & G & M3 & 0.89 & 0.05 \\
Potentilla gracilis & G & M4 & 0.86 & 0.01 \\
\hline
\end{tabular}

Notes: The M1 and M2 meadows are willow (Salix spp.) thickets and sedge (Carex spp.) marshes, respectively, with some ephemeral standing water. The M2 meadows have the highest graminoid biomass. The M3 meadows are mesic meadows characterized by high forb biomass and diverse forb and grass composition. The M4 meadows have cinquefoil (Potentilla spp.) and mixed herbaceous vegetation, while M5 meadows have a mixture of sagebrush (Artemisia tridentata) and herbaceous vegetation. The M6 meadows are characteristically xeric, rocky, and dominated by sagebrush.

(Cirsium scariosum, a native thistle) showed declining cover estimates from 1997 to 2007. The remaining 12 forb species showed declining trends, and these trends were primarily observed in mesic (M3) meadows. Species exhibiting significant trends were approximately evenly distributed between Gallatin and Teton sites. Only two woody species (Artemisia tridentata and Chrysothamnus viscidiflorus) and the cover class of bare ground showed significantly increasing trends. These trends were found in Gallatin M3 and Gallatin M5 meadows, respectively. Salix species showed no significant trends.

\section{DisCUSSION}

During the past decade, the GYE region experienced extended and extreme drought conditions. It is notable that our drought severity results are very different from the results presented by Gray et al. (2007), but their sampling period ends in 1999. The most intense drought conditions based on our PDSI measurements started in 2000. We observed heterogeneity in drought responses among plant functional groups and meadow types. However, the differences in responses were predictable based upon functional group and expected meadow-type sensitivity patterns. Forbs primarily showed decreases in percent cover, whereas woody plants showed increases in percent cover. We suspect that these differential responses are driven by differential use of deeper soil moisture. Deeper soil moisture is a more stable resource over time in this region (Hill et al. 2006, Prevey et al. 2009), resulting in less potential for interannual variation by plant species that use this moisture during drought conditions. Comparing responses across meadow types, we had predicted that mesic meadows would be most vulnerable to change, and our data supported this hypothesis. This response makes particular sense given that the mesic meadows show the highest seasonal production of forbs (Fig. 3).

We also documented differential responses within functional groups across the hydrological gradient. Dominant forbs showed a significantly different response in the M1 meadows compared to all other meadow types in the Gallatin region. We have observed that forbs are encroaching into hydric sites (D. M. Debinski, personal observation). Gallatin region meadows tend to be smaller than Teton region meadows, often by an order of magnitude, so we suspect that edge effects and spillover (e.g., Debinski et al. 2001) may factor into this potential for more rapid change in the Gallatin region. During this same time period, Gallatin meadows exhibited more significant changes in their butterfly communities than Teton meadows, and we expect that patch size effects may also be influencing these butterfly responses (Debinski et al. 2006, Caruthers 2008).

Shifts in montane meadow plant communities have been examined experimentally in warming experiments in the Northern Rocky Mountains (Harte and Shaw 1995) and the Tibetan Plateau (Klein et al. 2007). The Harte and Shaw (1995) as well as the Klein et al. (2007) sites involve experimental warming via heat lamps and are conducted at much finer geographic scales compared to our plots. However, all three studies have the common theme of examining plant community responses to drying conditions in montane meadows. The Northern Rocky Mountain experiment assessed changes as a function of rooting depths and found that shallowrooted forbs are particularly sensitive to warming, showing decreased aboveground biomass and flowering success in comparison to tap-rooted forb species (de Valpine and Harte 2001, Saavedra et al. 2003). When shallow-rooted forbs were experimentally removed, grasses and tap-rooted forbs increased in biomass (Cross and Harte 2007). Experimental warming of plant communities in the Tibetan Plateau resulted in shrubs replacing graminoids (Klein et al. 2007). The implications of these experimental findings are that the total herbaceous biomass production may be maintained under warming conditions, but it may be accomplished via an altered assemblage of plant species. Our data support a similar conclusion based upon differences in functional group responses of woody vs. forb species. 
We did not measure belowground changes in the plant community, but our aboveground responses indicate that a closer examination of such belowground responses would also be valuable.

The diversity of flowering plants is a critical asset to these meadow communities, from an aesthetic as well as a functional perspective. Changes in the plant community could have repercussions in the form of trophic cascades. Many of the individual forb species that showed declines in our study are important nectar sources, host plants for insect pollinators, or forage for mammalian herbivores. Lupinus serves as a host plant for Lycaenid butterflies, and Linum is an important nectar source for bees. Lupinus, Geum, and Erigonium all provide forage for mammals such as pocket gophers (Thomomys talpoides) (Keith et al. 1959). Linum lewisii provides forage for wildlife during spring and winter and birds use the seed and capsules in fall and winter (USDA NRCS 2006). Achillia and Geum have also been found to serve as food for sage grouse (Centrocercus urophasianus) (Martin 1970). Beyond the importance of diversity in the plant community are the issues of total biomass and quality of forage produced, which are important to the large herbivore populations that inhabit these regions. The experimental warming of Tibetan Plateau meadows resulted in an extension of the growing season but a reduction in both the forage nutritive quality and vegetative production (Klein et al. 2007).

Altered precipitation patterns can also have effects on the physiological processes and competitive relationships among vascular plants in this relatively xeric environment (Ehleringer et al. 2000), and these effects could have repercussions through the system. For example, long-term implications of drought may also include creating more favorable conditions for exotic species. Rinella et al. (2007) experimentally reduced grassland species richness by removing shallow- and/or deep-rooted forbs and/or grasses. They then introduced and monitored the performance of an invasive species, Centaurea maculosa. They concluded that intense disturbances, such as prolonged drought, that deplete multiple plant groups may be a prerequisite for the invasion of species such as C. maculosa. The only forb species that showed significant increases over time in our study was Cirsium scariosum, elk thistle. This species is not classified as a noxious weed (USDA NRCS 2006). However, its taproot (Kershaw et al. 1998) could make it more robust during times of decreased water availability and its spines may make it less palatable to herbivores. Cirsium scariosum is not found among the food plants included as elk diet in studies of either the Gallatin region (S. Creel, personal communication) or the Teton region (W. S. Fairbanks, unpublished data).

Stressed grassland systems in arid environments have been documented to show both increases and decreases in woody vegetation. Drier sites have been characterized by woody encroachment, whereas many hydric sites have been characterized by losses of woody species. The issue of encroachment of woody plants into grasslands is also one of the most prominent changes noted to occur in arid and semiarid systems over the past century (Throop and Archer 2008). In dryland systems, woody plants alter hydrological patterns, in part through their deeper rooting but also through their water use patterns (Throop and Archer 2008). Romme and Turner (1991) suggested that the Artemisia shrubs are likely to be increasing in abundance in the Greater Yellowstone Ecosystem. Our data support this prediction, but we also showed increases in the shrub Chrysothamnus viscidiflorus. Both of these shrubs have similar functional growth requirements and soil water use patterns (Kulmatiski et al. 2006).

Changes in percent cover of plants could also be affected by herbivory, so it is important to examine whether grazers and browsers play a role in attenuating or exacerbating the effects of drought on plant growth and community composition. Elk are the major herbivores in the meadows examined in this study, grazing on graminoids and forbs and browsing on woody species including Salix and Artemisia (W. S. Fairbanks, unpublished data). Elk numbers have been declining in the Gallatin region population since 1995 (Creel et al. 2005, 2007, Creel and Christianson 2008) and the Teton region elk population has similarly shown a downward trend from 1997 to 2007 based upon elk counts from the Buffalo Valley, Wyoming, and the National Elk Refuge (M. J. Kauffman, personal communication). The relative ratio of grazing to browsing by elk can also be modified by the presence of predators. Christianson and Creel (2008) showed that female elk (which form the majority of the population) increase browsing and decrease grazing when wolves are present, and a reduction in grazing could affect a behaviorally mediated trophic cascade from wolves to elk to plants. Thus, it is important to note that the reduction in forb cover we have quantified in the GYE during 1997-2007 occurred despite changes in elk numbers, habitat selection, and diet selection, which would all predict a release of forbs. The woody species we examined primarily showed an increasing response driven by Artemisia and Chrysothamnus. If these changes were driven by elk numbers, we would have expected decreasing trends, especially in the Salix spp., which generally is a taller shrub and provides more cover. We conclude that the plant community changes described in this work were predominantly driven by changes in drought conditions rather than herbivory.

\section{Conclusion}

Many models of climate change predict higher elevation and poleward shifts in species distributions. Our results have shown that species shifts may not be quite that simple. In a complex landscape, the effects of drought conditions on the plant community are not uniformly applied, but rather may be predicted based on 
landscape-level patterns of hydrological gradients and functional properties of plants that relate to use of shallow vs. deep stored water. Because the montane meadows used in this study are defined by soil moisture and soil moisture is intricately linked to the topographic position within the landscape, if climatic conditions become warmer and/or drier, these meadows may not be able to shift up in elevation because their location and moisture levels are tied to the topography and hydrology of the landscape. Thus, we expect that the resulting changes may be better defined within the short term as a shift in the mosaic of the landscape composition, including the associated plant communities, within an elevation rather than a shift in community relative to elevation. At some threshold level of climate change, we expect that these local responses will then translate into larger-scale responses along elevational gradients. However, these elevational changes may also be constrained by hydrological gradients.

\section{ACKNOWLEDGMENTS}

This material is based upon research supported by the National Science Foundation under Grants 0518150 and EPS0814387, the Environmental Protection Agency under STAR Grant R825155, the University of Wyoming National Park Service Research Station, and the Grand Teton Natural History Association. We thank the University of Wyoming National Park Service Research Station (particularly Henry Harlow and Sue Consolo-Murphy) and the U.S. Forest Service for providing support and housing. Philip Dixon provided statistical consulting, and Mark Jakubauskas collaborated in setting up our initial field campaigns. Edward Cook assisted in selection and assessment of PDSI data; and Lisa Graumlich, Andy Bunn, Steve Gray, and Jeremy Littel advised us on climate reconstruction options for the GYE. Scott Creel, Sue Fairbanks, and Matt Kaufmann provided information on elk population trends in the region. Jill Sherwood designed the map. William Clark and two anonomous reviewers provided important suggestions that helped improve the manuscript. Finally, we thank the many research technicians and field assistants who helped in the fieldwork.

\section{Literature Cited}

Caruthers, J. C. 2008. Butterfly community temporal trends and responses to resource availability along a hydrologic gradient of montane meadows. Thesis. Iowa State University, Ames, Iowa, USA.

Chesson, P. 2000. Mechanisms of maintenance of species diversity. Annual Review of Ecology and Systematics 31: 343-66.

Cook, C. W., and C. E. Lewis. 1963. Competition between big sagebrush and seeded grasses. Journal of Range Management 16:245-249.

Cook, E. R., R. Seager, M. A. Cane, and D. W. Stahle. 2007. North American drought: reconstructions, causes, and consequences. Earth Science Reviews 81:93-134.

Creel, S., and D. Christianson. 2008. Relationships between direct predation and risk effects. Trends in Ecology and Evolution 23:194-201.

Creel, S., D. Christianson, S. Liley, and J. Winnie. 2007. Effects of predation risk on reproductive physiology and demography in elk. Science 315:960.

Creel, S., J. A. Winnie, B. Maxwell, K. Hamlin, and M. Creel. 2005. Elk alter habitat selection as an antipredator response to wolves. Ecology 86:3387-3397.
Cross, M. S., and J. Harte. 2007. Compensatory responses to loss of warming-sensitive plant species. Ecology 80:740-748.

Daubenmire, R. F. 1959. Canopy coverage method of vegetation analysis. Northwest Science 33:43-64.

Debinski, D. M., M. E. Jakubauskas, and K. Kindscher. 1999. A remote sensing and GIS-based model of habitats and biodiversity in the Greater Yellowstone Ecosystem. International Journal of Remote Sensing 20:3281-3292.

Debinski, D. M., M. E. Jakubauskas, and K. Kindscher. 2000. Montane meadows as indicators of environmental change. Environmental Monitoring and Assessment 64:213-225.

Debinski, D. M., M. E. Jakubauskas, K. Kindscher, E. H. Saveraid, and M. Borgognone. 2002. Predicting meadow communities and species occurrences in the Greater Yellowstone Ecosystem. Pages 499-506 in J. M. Scott, P. J. Heglund, M. Morrison, M. Raphael, J. Haufler, and B. Wall, editors. Predicting species occurrences: issues of scale and accuracy. Island Press, Covello, California, USA.

Debinski, D. M., C. Ray, and E. H. Saveraid. 2001. Species diversity and the scale of the landscape mosaic: Do scales of movement and patch size affect diversity? Biological Conservation 98:179-190.

Debinski, D. M., R. E. VanNimwegen, and M. E. Jakubauskas. 2006. Quantifying relationships between bird and butterfly community shifts and environmental change. Ecological Applications 16:380-393.

de Valpine, P., and J. Harte. 2001. Effects of warming on a montane meadow ecosystem: how species responses comprise the ecosystem response. Ecology 82:637-648.

Dodd, M. B., W. K. Lauenroth, and J. M. Welker. 1998. Differential water resource use by herbaceous and woody plant life-forms in a shortgrass steppe community. Oecologia 117:504-512.

Ehleringer, J. R., S. Schwinning, and R. Gebauer. 2000. Water use in arid land ecosystems. Pages 347-365 in M. C. Press, J. D. Scholes, and M. G. Barker, editors. Physiological plant ecology. Blackwell Science, Oxford, UK.

Gray, S. T., L. J. Graumlich, and J. L. Betancourt. 2007. Annual precipitation in the Yellowstone National Park region since A.D. 1173. Quaternary Research 68:18-27.

Harte, J., and R. Shaw. 1995. Shifting dominance within a montane vegetation community: results of a climate-warming experiment. Science 267:876-880.

Hill, J. P., M. J. Germino, J. M. Wraith, B. E. Olson, and M. B. Swan. 2006. Advantages in water relations contribute to greater phyotosynthesis in Centaurea maculosa compared with established grasses. International Journal of Plant Science 167:269-277.

Jakubauskas, M. E., K. Kindscher, and D. M. Debinski. 1998. Multitemporal characterization and mapping of montane sagebrush communities using Indian IRS LISS-II imagery. Geocarto International 13:65-74.

Jakubauskas, M. E., K. Kindscher, and D. M. Debinski. 2001. Spectral and biophysical relationships of montane sagebrush communities in multitemporal SPOT XS data. International Journal of Remote Sensing 22:1767-1778.

Karl, T. R. 1986. The sensitivity of the Palmer Drought Severity Index and Palmer's Z-Index to their calibration coefficients including potential evapotranspiration. Journal of Applied Meteorology 25:77-86.

Keith, J. O., R. M. Hansen, and A. L. Ward. 1959. Effect of 2,4-D on abundance and foods of pocket gophers. Journal of Wildlife Management 23:137-145.

Kershaw, L., A. MacKinnon, and J. Pojar. 1998. Plants of the Rocky Mountains. Lone Pine Publishing, Edmonton, Alberta, Canada.

Kindscher, K., A. Fraser, M. E. Jakubauskas, and D. M. Debinski. 1998. Identifying wetland meadows in Grand Teton National Park using remote sensing and average wetland values. Wetlands Ecology and Management 5:265273. 
Klein, J. A., J. Harte, and X. Q. Zhao. 2007 Experimental warming, not grazing, decreases rangeland quality in the Tibetan Plateau. Ecological Applications 17:541-557.

Knowles, N., M. Dettinger, and D. Cayan. 2006. Trends in snowfall versus rainfall for the western United States. Journal of Climate 19:4545-4559.

Kulmatiski, A., K. H. Beard, and J. M. Stark. 2006. Exotic plant communities shift water-use timing in a shrub-steppe ecosystem. Plant and Soil 288:271-284.

Marston, R. A., and J. Anderson. 1991. Watersheds and vegetation of the Greater Yellowstone Ecosystem. Conservation Biology 5:338-346.

Martin, N. S. 1970. Sagebrush control related to habitat and sage grouse occurrence. Journal of Wildlife Management 34: 313-320.

Mote, P. W., A. F. Hamlett, M. P. Clark, and D. P. Lettenmaier. 2005. Declining mountain snowpack in western North America. American Meteorological Society 86:39-49.

National Climate Data Center. 2009a. Time bias-corrected divisional temperature-precipitation-drought index. 〈http:// www7.ncdc.noaa.gov/CDO/CDODivisionalSelect.jsp

National Climate Data Center. 2009b. Surface inventories/station lists. 〈http://www.ncdc.noaa.gov/oa/climate/ surfaceinventories.html $\rangle$

Noy-Meir, I. 1973. Desert ecosystems: environment and producers. Annual Review of Ecology and Systematics 4: 25-51.

Prevey, J. S., M. J. Germino, N. J. Huntly, and R. S. Inouye. 2009. Exotic plants increase and native plants decrease with loss of foundation species in sagebrush steppe. Plant Ecology. [doi: 10.1007/s11258-009-9652-x]

Reiners, W. A., et al. 2003. Natural ecosystems 1. The Rocky Mountains. Pages 145-184 in F. Wagner and T. Stohlgren, editors. Preparing for a changing climate: the potential consequences of climate variability and change. Rocky Mountain/Great Basin Regional Assessment Team for the U.S. Global Change Research Program, Utah State Press, Logan, Utah, USA.
Richards, J. H., and M. M. Caldwell. 1987. Hydraulic lift: water efflux from upper roots improves effectiveness of water uptake by deep roots. Oecologia 73:486-489.

Rinella, M. J., M. L. Pokorny, and R. Rekaya. 2007. Grassland invader responses to realistic changes in native species richness. Ecological Applications 17:1824-1831.

Romme, W. H., and M. G. Turner. 1991. Implications of global climate change for biodiversity in the Greater Yellowstone Ecosystem. Conservation Biology 5:373-386.

Saavedra, F., D. W. Inouye, M. V. Price, and J. Hart. 2003. Changes in flowering and abundance of Delphinium nuttallianum (Ranunculaceae) in response to a subalpine climate warming experiment. Global Change Biology 9:885-894.

Saunders, S., C. Montgomery, T. Easley, and T. Spencer. 2008. Hotter and drier: the West's changed climate. Rocky Mountain Climate Organization and the Natural Resources Defense Council, New York, New York, USA.

Saveraid, E. H., D. M. Debinski, K. Kindscher, and M. E. Jakubauskas. 2001. A comparison of satellite data and landscape variables in predicting bird species occurrences in the Greater Yellowstone Ecosystem. Landscape Ecology 16: 71-83.

Sturges, D.L 1973. Soil moisture response to spraying big sagebrush the year of treatment. Journal of Range Management 26:444-447.

Throop, H. L., and S. Archer. 2008. Interrelationships among shrub encroachment, land management, and litter decomposition in a semidesert grassland. Ecological Applications 17: 1809-1823.

USDA NRCS [U.S. Department of Agriculture Natural Resources Conservation Service]. 2006. Plants database. $\langle$ http://plants.usda.gov $\rangle$

Williams, D. G., and J. R. Ehleringer. 2000. Intra- and interspecific variation for summer precipitation use in pinyon-juniper woodlands. Ecological Monographs 70:517537. 